The Mutation Factor in Evolution, published in 1915. He had strong and lasting views on the significance of mutations, not least those of large effect, in evolution, a view expressed in his Mutations and Evolution (1921).

The most important early work of Gates was the discovery (independently made by Miss Lutz) that the gigas mutant was tetraploid, with twice the chromosome number of the normal species. He also found triploid and trisomic mutants and the dominant rubricalyx, but the tetraploid was of especial interest since it had arisen directly from the normal diploid, differed from it in certain small characters and was isolated from it reproductively, hybrids between diploid and tetraploid being infertile. This first discovered instance of autototraploidy was a great stimulus to further research. His later work was on the evolution of the wild species of 2 Enothera, differing from one another only slightly, true breeding but easily crossed artificially, and perhaps rather impermanent in nature. In it he came to accept the views of Renner, Darlington and Cleland, though grudgingly and preserving somo of his own earlier misconceptions. The disagreements which were involved at least served to stimulate useful research.

Early in his scientific life, Gates developed a keen interest in human genetics and evolution and anthropology. His books, Heredity and Eugenics (1923) and Heredity in Man (1929), were good introductions to their subjects and undoubtedly stimulated many peoplo to gain an interest. Later, he published an immense two-volume compilation, Human Genetics (1946), followed by Human Ancestry (1947) and Pedigrees of Negro Families (1949). $\mathrm{He}$ was particularly interested in primitive peoples, collecting data on blood groups and other characteristies; more recently he investigated the genetics of skin pigmentation in negroids.

Gates was an inveterate traveller, whether collecting Enothera species in North America or traversing Africa in the pursuit of anthropological data. Travelling, indeed, was his sole recreation and one he never relinquished; in his seventies he visited Cuba, Mexico, Japan, Africa, Australia and India in furtherance of his studies of primitive peoples. $A$ Botanist in the Amazon Valley (1927) records observations which were often recounted to appreciativo undergraduate classes.

In outlook, Gates was primarily an observer, describer and systematist. Ho made experiments rather blindly, for he had little capacity for conceiving scientific hypotheses and for devising experimental tests. His early work, which was his best, was observational. He had a strong faith in what the microscope would reveal to his eye, scorning theoretical principles which controverted these observed 'facts'. His research students were closely supervised and expected daily to demonstrate a good cytological preparation; they were well trained in microscopical techniques, though conservatively.

As a colleague he was difficult to get to know at all intimately, for he seemed unable to relax and be at ease. Though generally mild-mannered, he could be most stubborn and would rarely admit to an error or retract a viow previously expressed. Through scientific controversy, not always on the right side, and his abundant writings, he certainly stimulated scientific thought and research.

His first wife was the late Dr. Marie Stopes, the well-known botanist and pioneer advocate of birth control and sex education; this marriage was annulled.
In 1930 he married Miss Jenny Williams, the singer, and in 1955 he married Mrs. Laura Greer (née Nowotny) of Texas. D. G. CATCheside

\section{Prof. F. P. Dwyer}

Prof. F. P. Dwyer, head of the Biological Inorganic Chemistry Unit in the Australian National University, died suddenly at his home in Canberra on June 22, from a coronary occlusion, at the age of fifty-one years.

Prof. Dwyer was born at Nelson Plains, New South Wales, and was educated at the Marist Brothers' Col. lege, Maitland, and the University of Sydney, where he graduated in 1932. From 1934 until 1945 he was senior lecturer and head of the Inorganic Chemistry Department at the Sydney Technical College, and during 1945-46 he was senior lecturer in inorganic chemistry in the University of Sydney. He was a visiting professor at Northwestern University during 1953-54, and in 1956 he was appointed to a new chair in inorganic chemistry in Pennsylvania State University; but he resigned from this appointment in 1957 without taking up the post to become reader and head of the Biological Inorganic Chemistry Unit in the John Curtin School of Medical Research of the Australian National University. For his outstanding contribution to inorganic chemistry he was elected, in 1960 , to one of the first personal professorships created in the Australian National University.

The versatility of Prof. Dwyer and the breadth of his interests in research are shown by more than 150 publications spread over the following topies: X-ray analysis, micro-analytical reagents and procedures, isomerism of the triazines and diazoamino compounds and their metal derivatives, the chemistry of platinum, palladium, rhodium, iridium, ruthenium and osmium, the redox potentials of simple compounds and complexes of the platinum metals, the optical activity and kinetics of racemization and substitution of Group 8 metal complexes, the diastereoisomeric offect and the principle of configurational activity, the stereochemistry of multidentate chelates, electron transfer reactions, the effects of metal complexes in biological systems and stereospecific influences in octahedral complexes.

For his work on diazoamino compounds, their metallic salts and metallic hydroxide lakes, he was awarded the degree of D.Sc. of the University of Sydney, the Royal Australian Chemical Institute's Rennie Medal (1940) and the Smith Medal (1945). In 1953 he was awarded the University of Melbourne's David Syme Medal and Prize for distinguished work in natural science.

In later years, as his international reputation grew, he held the George Fisher Baker non-resident lectureship in Cornell University (1954) and the first Chemical Society lectureship instituted by the Chemical Society of London for the purpose of encouraging the study of chemistry in Australian universities. Shortly before he died he had given a series of lectures at the invitation of the American Chemical Society. $\mathrm{He}$ is survived by his widow, two sons and a daughter.

Prof. Dwyer's colleagues will remember him for his outstanding ability, his personal charm, friendliness and modesty. His students will remember not only these qualities, but also his unfailing cheerfulness, sense of humour, encouragement and enthusiasm in the face of their many problems and errors. Scientifically, he is a great loss and he leaves many sad friends.
A. SARgEson 